\title{
Evaluation of acute postoperative pain control and identification of risk factors - experience in a tertiary care center
}

CENTRO HOSPITALAR
LISBOA NORTE. EPE

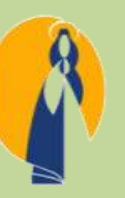

ALBUQUERQUE, José Diogo ${ }^{1}$; ABECASIS, Manuel Rocha ${ }^{1}$; RESENDE, Alexandra²

\section{BACKGROUND AND GOAL OF STUDY}

Postoperative pain is quite common and most patients report poor pain control in the post-operative period, which is linked with worse outcomes. The complexity of acute pain led to the development of acute pain services (APS). Currently there is no optimal model for APS.

In our institution, we developed an PACU-based anesthesiologist-led
APS that is responsible for pain management of patients under PCAs or regional catheter-based analgesia and in physician-referred patients.

The aim of this study is to:

- Evaluate post-operative pain control in our institution.

- Identify risk-factors and areas for improvement.

\section{MATERIALS AND METHODS}

During one week period, we assessed all patients who were admitted to our central postanaesthetic care unit for:

- $\quad$ RRS at 0 and 24hrs;

- Age;

- Type of surgery;

- Type of anaesthesia;
- Type of post-operative analgesia;

- In-PACU time;

Statistical analysis was performed using SPSS 2.0 and we applied $\chi$ /f-Fisher tests and t-Student/Mann-Whitney tests, considering $p$ value $<0,05$

\section{RESULTS AND DISCUSSION}

\begin{tabular}{|c|c|c|c|c|c|}
\hline & \multicolumn{2}{|l|}{$n=101$} & & \multicolumn{2}{|c|}{$n=101$} \\
\hline \multirow{2}{*}{ Gender } & 우 & 47 & \multirow{3}{*}{ Pain at PACU admission } & Mild & $82 \%$ \\
\hline & $\sigma^{7}$ & 54 & & Moderate & $10 \%$ \\
\hline Age & \multicolumn{2}{|c|}{$67(23-95)$} & & Severe & $8 \%$ \\
\hline \multirow{3}{*}{$\begin{array}{l}\text { Anaesthesia } \\
\text { technique }\end{array}$} & GA & $80 \%$ & \multirow{3}{*}{ Pain at day 1 after surgery } & Mild & $56 \%$ \\
\hline & RA & $15 \%$ & & Moderate & $33 \%$ \\
\hline & Sedoanalgesia & $2 \%$ & & Severe & $11 \%$ \\
\hline \multirow{3}{*}{$\begin{array}{c}\text { Post- } \\
\text { operative } \\
\text { analgesia }\end{array}$} & $\begin{array}{c}\text { Intravenous (+PCA |+wound } \\
\text { infiltration) }\end{array}$ & $73 \%(1 \% \mid 2 \%)$ & \multirow{4}{*}{\multicolumn{2}{|c|}{$\begin{array}{l}\text { Pain at } 0 \text { hrs had statistically significant relation to: } \\
\text { - } \quad \text { Age }(p=0,007) \text {; } \\
\text { - } \quad \text { Anaesthetic technique }(p=0,002) \\
\text { Pain at } 24 \text { hrs was related to: } \\
\text { - } \quad \text { Age }(p=0,002) \\
\text { - Pain at } 0 \text { hrs }(p=0,002)\end{array}$}} & \\
\hline & Epidural (PCEA) & $12 \%(1 \%)$ & & & \\
\hline & Peripheral nerve block & $11 \%$ & & & \\
\hline & & & & & \\
\hline
\end{tabular}

\section{CONCLUSION}

With this study we were able to see that there is room for improvement in postop pain control in our institution.

Our data also suggest:

- As expected regional anaesthesia is associated to better immediate postoperative pain control, but not with pain at $24 \mathrm{hrs}$;

- Good early pain control was associated with better pain control at 24 hours;

- The later may be an important predictor of post-operative pain control;

- Age was associated with worse post-operative pain control.

This study suggests important predictors of poor pain control that could be used as criteria for APS referral:

- Age;

- pain upon PACU admission. 